\title{
NÃO SEI SE VOU, OU SE FICO: DILEMAS DETERMINANTES ENTRE SER OU NÃO SER UM CENTRO UNIVERSITÁRIO
}

\author{
I DO NOT KNOW IF I GO, OR MAKE MYSELF: DETERMINING DILEMMAS BETWEEN BEING OR \\ NOT BEING A UNIVERSITY CENTER
}

\author{
Recebido em 28.10.2020 Aprovado em 23.11.2020 \\ Avaliado pelo sistema double blind revien \\ DOI: $\underline{\text { https://doi.org/10.32888/cge.v8i3.46966 }}$
}

\author{
Dra. Antônia Márcia Rodrigues Sousa \\ pesquisadoramarciarodrigues@gmail.com \\ Programa de Graduação em Ciências Econômicas /Universidade Federal do Ceará (UFC) \\ https://orcid.org/0000-0003-0659-9897
}

\author{
MSc. Ruan Carlos dos Santos \\ ruan_santos1984@hotmail.com \\ Programa de Graduação e Tecnologia em Gestão Financeira/Centro Universitário UNIAVAN \\ Doutorado em Administração/UNIVALI \\ https://orcid.org/0000-0003-0659-9897
}

\section{Resumo}

Este caso relata a trajetória de um empreendedor destemido que identificou, em meio às dificuldades de uma cidade no interior do Ceará, a oportunidade de fundar em 2007 uma Instituição de Ensino Superior, que vem apresentando indicadores que contribuem para superar tais desafios e se colocar no mapa da Educação do Brasil, tornando-se um Centro Universitário. Os dados foram coletados por meio de entrevistas semiestruturadas com o fundador professor Luciano Feijão e o suporte de documentos fornecidos pela instituição educacional. Sugere-se que o caso seja utilizado em curso de graduação em Administração ou áreas afins, especificamente nas disciplinas de Empreendedorismo, Tomada de decisão e Processo decisório. Justifica-se o uso do caso nessas disciplinas por estimular os alunos a refletir e relacionar o contexto teórico com a prática gerencial a partir de uma análise sobre os comportamentos, perfil e características empreendedoras, e a capacidade de tomada de decisão do gestor que atua em um segmento altamente competitivo de mais oferta que demanda.

Palavras-chave: Empreendedorismo. Tomada de Decisão. Ensino Superior.

\begin{abstract}
This case for education relates the story of a fearless entrepreneur who identified among the difficulties of a city in the interior of Ceará, the opportunity to establish in 2007 a higher education institution that has shown potential indicators that may help to overcome these challenges and put on the map of Education of Brazil, becoming a University Center. Data were collected through semi-structured interviews with Professor Founder Luciano Beans and document support provided by the company. It is suggested that if used in undergraduate degree in Business Administration or related fields, specifically in Entrepreneurship disciplines, decision-making and decision-making process. Justifies the use of the case in these disciplines to stimulate students to reflect and relate the theoretical context with management practice from an analysis of the behavior, profile and entrepreneurial characteristics, and the manager's decision-making capacity that operates in a highly competitive segment more supply than demand.
\end{abstract}

Keywords: Entrepreneurship. Decision Making. Higher education. 


\section{O prelúdio}

Um professor de matemática com a pedagogia e a autonomia de Paulo Freire, "exigindo no ensinar a rigorosidade metódica, o respeito aos saberes, a criticidade, a ética, a corporificação das palavras pelo exemplo e com a certeza de que não há docência sem discência". Assim é o matemático e pedagogo de formação, professor Luciano Feijão, natural de Fortaleza, nascido em 1942. Mudou-se para a cidade de Sobral a $240 \mathrm{~km}$ de Fortaleza em 1968, para lecionar no Colégio Estadual Dom José Tupinambá da Frota.

Possuidor de um espírito aguerrido e empreendedor, o professor Luciano Feijão, nos idos dos anos de 1969, começou a construir, na cidade de Sobral, uma escola diferente, com uma nova filosofia e um projeto pedagógico inovador, suplantando as intempéries e as adversidades típicas de uma região incrustada no semiárido nordestino. Em 1970, formalmente o professor Luciano Feijão criou o Colégio de Ensino Fundamental e Médio Luciano Feijão, que traz, em seu nome, a marca de seus objetivos e fortes traços da personalidade do homem que simboliza a história da constante construção de uma educação fundamentada no respeito e saberes do educando.

Seguindo os ideais de Paulo Freire (1996), ao afirmar que "ensinar exige o reconhecimento e a assunção da identidade cultural", com essa convicção, o professor Luciano Feijão paulatinamente foi construindo sua história na educação de Sobral, como professor e gestor, atuou de 1972 a 1975 como Secretário de Educação do município. Em 1977, concomitante com o trabalho como professor e gestor do Colégio, ingressou no poder legislativo com a obtenção de uma cadeira de vereador do município de Sobral, ocupando-a, sucessiva e ininterruptamente, durante oito legislaturas. Atuou em (1982) como Presidente da Câmara do Município de Sobral por duas vezes.

No período de 1982 a 1984, assume novamente o cargo de Secretário de Educação do Município de Sobral. Nessa mesma época, usou da sua experiência como educador e de seus laços sociais, para implantar o Ensino Médio nos municípios de Massapê, Forquilha e Moraújo, cidades circunvizinhas de Sobral.

Em consonância com o fazer e vivenciar a educação, atuou no Poder público sempre buscando melhorias para a qualidade dos ensinos fundamental e médio do município. Essa dupla experiência fez que o professor Luciano Feijão identificasse que o crescimento da cidade de Sobral não estava atendendo as necessidades da população em relação à continuidade na formação educacional.

Como gestor-fundador do Colégio de Ensino Fundamental e Médio Luciano Feijão desde 1969, e que, na década de 2000, já era uma potência em qualidade de educação passando a configurar-se como uma das melhores instituições de ensino fundamental e médio do estado do Ceará. $O$ alcance nessa categoria de alta competitividade levou o professor Luciano Feijão a identificar novas oportunidades no segmento da educação, agora, com uma conotação voltada para contribuir na formação de novos profissionais.

Assim em 2003, iniciou a implantação dessa ideia com a formação de uma equipe de profissionais que passaram a analisar os aspectos potenciais da região para a criação de uma Instituição de Ensino Superior privado, dando origem à Faculdade Luciano Feijão, instituição idealizada no ano de 2003, com o Projeto de Desenvolvimento Institucional implantado no sistema do Ministério da Educação, no início de 2004, publicado em 2005. Oficialmente, as atividades de ensino iniciaram em abril de 2007, após a publicação da portaria de autorização de funcionamento dos cursos de Direito e Administração.

Em 2008, a instituição já tinha, em seu organograma, um setor de pesquisa e extensão, formando o tripé do ensino superior. A integração entre ensino, pesquisa e extensão contribuiu para o crescimento em número de alunos e na integração em 2011 do curso de Psicologia.

Em 2015, foi autorizado o curso de Engenharia Civil. No mesmo período, inicia-se o processo logístico para receber a fiscalização para autorização do curso de Enfermagem. Comungando com o crescimento da graduação, a pós-graduação lato sensu oferta cursos de especialização nas áreas de Direito e Administração atendendo a demanda dos egressos e demais interessados.

Pela natureza da Instituição, ainda não é possível um mestrado próprio, assim para suprir a necessidade da região, firmou-se, em 2015, uma parceria para oferta do primeiro Mestrado Interinstitucional em Administração no Ceará, com a Universidade Vale do Itajaí-UNIVALI. No mesmo período, fecha-se a parceria com a Universidade Federal de Santa Catarina-UFSC, para oferta do Mestrado Interinstitucional em Direito.

No planejamento institucional de 2016, consta-se a oferta do primeiro vestibular em Engenharia Civil e a formação da equipe para análise e construção do projeto para o curso de Medicina, enquanto se aguarda a autorização do curso de Enfermagem. 
Diante deste cenário, o professor Luciano Feijão vive os seguintes dilemas: permanecer como uma Faculdade isolada com oferta limitada de Cursos Superiores? Investir em novos cursos para chegar a Centro Universitário o mais rápido possível? Ou fortalecer os investimentos nos cursos em funcionamento?

\section{Identificando oportunidades para superar obstáculos}

O Colégio de Ensino Fundamental e Médio Luciano Feijão fundado em 1969, surgiu de uma oportunidade percebida pelo professor Luciano Feijão, visando atender a realidade sobralense que, naquele momento, estava carente de ideais novos de educação. Sua construção foi feita de forma dinâmica, embora tenha sido necessário superar algumas adversidades; sempre com a preocupação voltada para uma base sólida da instituição.

Desde a sua fundação, o colégio esteve intimamente ligado ao compromisso com a sociedade sobralense de garantir uma alternativa estruturada de ensino acessível a nossa população.

Após os primeiros desafios, o centro de educação transformou-se em referência absoluta de qualidade e estrutura, não apenas para a sociedade sobralense, mas para todo o estado do Ceará; tornando-se perceptível pela quantidade de alunos que chegam, a cada ano, para se formarem nesta instituição, vindos de outras cidades.

A primeira localização do colégio lembra a simplicidade que marcou os primeiros anos de sua história. Naquela época, o professor Luciano, que ativou seu sonho a partir de um projeto de criação de colégios no interior, apoiado pelo Governo do Estado do Ceará, ficou com responsabilidades acumuladas; era responsável, inclusive, pelo transporte dos professores, de vários bairros, até a sede do colégio.

Na década de 1970, o colégio ainda não disponibilizava ensino para todas as séries da educação básica. O primeiro foco educacional estava ligado a turmas noturnas, de educação de jovens e adultos e dos famosos cursos "normais". Os colégios municipais funcionavam apenas em um turno, o que propiciava a formação de uma nova instituição à noite. Essa dura missão e a humilde localização escondiam a vitória que se concretizaria apenas anos depois.

Houve, então, uma mudança de sede, e o colégio passou a funcionar no prédio da "Escola Pública João Ribeiro Ramos", localizada na Travessa Tabelião Ildefonso Cavalcante. Nesse novo espaço, persistem histórias que simbolizam a resistência do Professor Luciano e de seu colégio às adversidades oferecidas pelo contexto social da época.

Narra-se, constantemente, o episódio em que o professor Luciano Feijão chega ao colégio e defronta-se com a estrutura "limpa", ou seja, com recursos materiais administrativos necessários para o pleno funcionamento das aulas. Isso fora o sinal para uma nova mudança que viria.

Em 1977, o Professor Luciano Feijão constituiu o Centro Social "Clodoveu Arruda", objetivando fundar uma associação sem fins lucrativos, para que se pudesse manter o Colégio de Ensino Fundamental e Médio Luciano Feijão e, assim, beneficiar os alunos e a comunidade da cidade de Sobral.

Durante quinze anos (1969 - 1984) de constante luta e reafirmação, o Colégio de Ensino Fundamental e Médio Luciano Feijão, finalmente, chegou ao local onde se situa até hoje. As instalações, que ficam na Avenida Dom José (Bispo de renome e símbolo de educação em Sobral), passaram por um processo dinâmico de expansão.

\section{Trilhando novos caminhos e superando desafios}

A fundação do Centro Social Clodoveu Arruda, mantenedora do Colégio de Ensino Fundamental e Médio Luciano Feijão, concretizou a afirmação da proposta educacional de excelência, idealizada pelo Professor Luciano Feijão e posta em prática por muitas mãos e mentes, que dedicaram e ainda dedicam boa parte de suas vidas à realização de um sonho pensado e concretizado em equipe.

A partir de janeiro de 1984, iniciou-se o processo de transformação estrutural do Colégio de Ensino Fundamental e Médio Luciano Feijão. Nesse momento também foi de muitas histórias que ainda permeiam a memória de tantas pessoas.

A compra do terreno veio a partir de uma transação imobiliária que envolvia quatro casas do Professor Luciano e uma quantia em dinheiro, em troca do terreno tão sonhado. Este sonho escondia, atrás das cercas de madeira, uma realidade nada animadora: muitas casas da Rua Dom José enviavam seu sistema de escoamento para aquele local. A construção de uma nova rede de esgotos possibilitou a drenagem do terreno. Assim, com a solução do empecilho que retardava a edificação do prédio, o sonho de construir uma escola começava a tomar corpo. 
Iniciou-se pelo aterramento de uma lagoa para a construção do Colégio, fato que gerava muitas especulações por parte dos engenheiros práticos em relação à sustentabilidade do terreno.

A construção do Colégio de Ensino Fundamental e Médio Luciano Feijão envolveu muitos esforços dos seus idealizadores. Após tantos obstáculos, iniciaram-se, enfim, as aulas, apesar de o prédio ainda não estar finalizado e de, por isso, oferecer, naquele momento, uma estrutura humilde. Esses obstáculos, como os outros, foram superados.

Assim, a instituição conseguiu, finalmente, alcançar novos horizontes e, desde então, é a referência máxima em educação sobralense. Passou por reformas ainda nos anos 1990; também adquiriu um prédio anexo, que oferta mais possibilidades de desenvolvimento aos alunos.

Nos anos 2000, com a chegada do novo século, surgiram novos desafios e mais crescimento. O prédio central viu, então, o surgimento de um anexo criado para receber, em 2005, a instituída Faculdade Luciano Feijão.

\section{Uma travessia com oportunidades e dificuldades disfarçadas: cria-se a Faculdade Luciano Feijão}

O crescimento social e econômico do estado do Ceará sinalizava a necessidade de uma expansão do ensino superior privado no interior. Em consonância, Sobral passava por uma evolução econômica impulsionada pela visão contemporânea do gestor municipal, Cid Ferreira Gomes, que, no ano de 2005, encerrava uma gerenciamento com prospecção futura de grande desenvolvimento econômico e social.

Na perspectiva de novas oportunidades, e envolvido pelo sucesso do colégio, o professor Luciano Feijão, com o desejo de realização associado ao estabelecimento da ideia do novo negócio, lançou-se ao desafio de construir, no ano de 2005, a primeira Faculdade Privada da Região Noroeste do Estado do Ceará. Após dois anos de árdua batalha, fortalecidos pelo idealismo e pela perseverança, fez nascer a Faculdade Luciano Feijão, com a publicação de credenciamento pela Portaria de n. ${ }^{\circ} 3.918$, de 14 de novembro de 2005, para funcionamento na Avenida Dom José, n. ${ }^{\circ} 325$, centro, na cidade de Sobral-Ceará.

No mesmo período, foi autorizado pela Portaria n. ${ }^{\circ}$ 3.919, de 14 de novembro de 2005, o funcionamento dos cursos de bacharelados em Administração e Direito, ambos com duzentas vagas anuais, para funcionamento nos turnos diurno e noturno.

Em abril de 2007, inaugura-se, no Centro de convenções de Sobral, sob aplausos e discursos de grandes membros da comunidade acadêmica e da política do Ceará, a Faculdade Luciano Feijão.

O evento contou com a presença de mais de 300 pessoas e com a receptividade da sociedade, com a chegada da primeira instituição de ensino superior privado em Sobral. Até então, muitas famílias mantinham seus filhos estudando em Fortaleza, por não ter uma oferta de ensino superior privado em Sobral.

Assim, iniciaram-se as atividades acadêmicas da Faculdade Luciano Feijão, com 100 alunos matriculados no curso de Direito, nos turnos da tarde e noite; 100 alunos matriculados no curso de Administração no turno da noite, e uma lista de espera de mais 200 discentes classificáveis em Direito, na perspectiva de entrar na vaga de um desistente.

A Faculdade Luciano Feijão tem um alcance geográfico envolvendo não só a Cidade de Sobral, como também um universo de 46 (quarenta e seis) municípios em torno da região norte do Estado, os quais compõem as Macrorregiões Administrativas Sobral/Ibiapaba e Litoral Oeste, com população estimada em 1.500 .000 habitantes (IPECE / Anuário Estatístico do Ceará, 2008; dados de 2007), o que possibilitou o fortalecimento, ao longo do tempo, como um centro de referência em todo o Estado do Ceará e demais Estados vizinhos, essa instituição forma profissionais com competências e habilidades, críticos, éticos e técnico-científicos, conscientes da importância da formação profissional, voltada para a assistência, o Ensino, a Pesquisa e a Extensão em todos os níveis.

Os cursos de graduação da Faculdade Luciano Feijão contemplam uma formação ampla, com estímulo ao pensamento crítico, vinculam os conteúdos trabalhados com o contexto político, econômico, social e cultural da sociedade. Oferecem formação teórico-metodológica, garantida pelo aprofundamento das matrizes do conhecimento que embasam as profissões, de acordo com avanços científicos, tecnológicos e sociais das respectivas áreas. Cumprem as exigências da Lei de Diretrizes e Bases da Educação Nacional e das Resoluções relativas ao Ensino Superior emanado do Conselho Estadual de Educação (CEE), bem como atendem às Diretrizes Curriculares Nacionais e demais normatizações correlacionadas, de ordem do Conselho Nacional de Educação (CNE). 
Para alcançar seus objetivos, a Política de Graduação da Faculdade Luciano Feijão é desenvolvida de forma articulada à Política de Pesquisa e Extensão institucional, à projeção e melhoria de espaços acadêmicos como laboratórios, salas especiais, biblioteca, acervo, entre outros. Também trabalha de forma permanente com educação continuada de docentes, estímulo ao desenvolvimento de novas metodologias e tecnologias de ensino, ao aprimoramento dos processos curriculares, em especial os estágios e os processos avaliativos. Busca aperfeiçoar cotidianamente os serviços disponíveis aos (às) universitários (as) através da Secretaria Acadêmica, do Programa de Integração de Estágios e do Programa de Atendimento aos Estudantes.

No âmbito da Pós-Graduação lato sensu (especialização), são oferecidos cursos com vistas ao atendimento de demandas regionais específicas por qualificação profissional, e programas permanentes, articulados às áreas prioritárias definidas na Política de Pós-Graduação e linhas de pesquisa das Áreas. Dentro desse contexto, a construção de uma mentalidade científica, através da ampliação e qualificação do quadro docente torna-se imperativa para a afirmação da atitude investigativa no espaço universitário e consequente aumento da produção científica e ampliação dos grupos de pesquisa na Instituição (PDI, 2011).

No percurso de 2007 a 2015, estas ações para a melhoria do ensino, pesquisa e extensão foram realizadas em um espaço com setores adaptados no prédio anexo ao Colégio Luciano Feijão. Tais adaptações não comprometeram a qualidade da educação, pois desde a sua criação foi disseminado que o nascer de uma Instituição de Ensino Superior é mais um lócus de conhecimento em que se inserem relações complexas e adaptativas nos mais diversos âmbitos.

Compreende-se que uma infraestrutura específica para a oferta do ensino superior fortalece a aplicação e a congruência do processo de ensino, pesquisa e extensão. Portanto, embalado pelo desejo dessa mudança, planejase uma nova sede para a Faculdade Luciano Feijão.

\section{Empreendimento novo, adaptações novas: a mudança para nova sede}

Em uma linha temporal cronometrada tal qual o pulsar de um ponteiro marcando os segundos de forma precisa e estável, o professor Luciano Feijão sonhou, idealizou e planejou, durante oito anos, um espaço de fazer educação superior de forma diferenciada. E, com um olhar de gratidão, deixou para trás o terreno fértil que germinou e acolheu a Faculdade Luciano Feijão, seguindo, então, para a nova sede.

O professor Luciano Feijão, como um exímio gestor, reconhece que a inserção econômica e social de um negócio é balizada por uma história de relações e formação de rede que se completam ao mobilizarem esforços para obter recursos necessários para implementá-las.

Nessa ótica, iniciou solenemente, no dia 28 de janeiro de 2016, às 20h00min no horário de Brasília, na cidade de Sobral, Ceará, a inauguração da nova sede da Faculdade Luciano Feijão.

O fundador-empreendedor, professor Luciano Feijão, ao fazer uso da palavra visivelmente emocionado, iniciou seu discurso, agradecendo o apoio da familia e pontualmente fez referência em ordem cronológica por nome, cargo e órgão a cada uma das pessoas que contribuíram para a efetivação daquele momento.

Presenciou-se um momento de demonstração de gratidão e de exposição da história de um homem que, há mais de quarenta anos, oferece um dos serviços mais importante para a população, a educação. Na ocasião, o professor Luciano Feijão relembrou sua história como político eleito por oito mandatos na ocupação de uma vaga na Câmara Municipal de Sobral, momento que exaltou suas fortes características de um ser humano íntegro, ético e firme nas suas decisões.

Em uma linha temporal cronometrada tal qual o pulsar de um ponteiro marcando os segundos de forma precisa e estável, o professor Luciano Feijão sonhou, idealizou e planejou, durante oito anos, um espaço de fazer educação superior de forma diferenciada. Ele, com um olhar de gratidão, deixou para trás o terreno fértil que germinou e acolheu a Faculdade Luciano Feijão, seguindo, então, para a nova sede.

O professor Luciano Feijão, como um exímio gestor, reconhece que a inserção econômica e social de um negócio é balizada por uma história de relações e formação de rede que se completam ao mobilizarem esforços para obter recursos necessários para implementá-las.

Nessa ótica, iniciou solenemente, no dia 28 de janeiro de 2016, às 20h00min no horário de Brasília, na cidade de Sobral, Ceará, a inauguração da nova sede da Faculdade Luciano Feijão. 
O fundador-empreendedor, professor Luciano Feijão, ao usar ao proferir, iniciou seu discurso, agradecendo o apoio da família e pontualmente fez referência em ordem cronológica por nome, cargo e órgão a cada uma das pessoas que contribuíram para a efetivação daquele momento.

Presenciou-se um momento de demonstração de gratidão e de exposição da história de um homem que, há mais de quarenta anos, oferece um dos serviços mais importante para a população, a educação. $\mathrm{Na}$ ocasião, o professor Luciano Feijão relembrou sua história como político eleito por oito mandatos na ocupação de uma vaga na Câmara Municipal de Sobral, momento que exaltou suas fortes características de um ser humano íntegro, ético e firme nas suas decisões.

Como um gestor experiente, o professor Luciano Feijão reconheceu a importância de um boa equipe para realização de grandes jogadas e muitas vitórias ao pontuar a capacidade de liderança da diretora-geral da Faculdade, Prof. ${ }^{a}$ Isabel de Aguiar Pontes, dos coordenadores de cada curso, professores e funcionários.

Ao mesmo tempo, demonstrou expectativa em relação à continuidade do seu modelo de gerenciamento, já que agora estava mudando para um espaço exclusivo para o gerenciamento da nova sede da Faculdade Luciano Feijão. Passando, então, a gerenciar uma instituição com uma área total de $22.000 \mathrm{~m} 2$, sendo $15.000 \mathrm{~m}^{2}$ de área construída, dividida em 05 pavimentos. Contando com uma estrutura de 40 salas de aula; 01 auditório; 01 grande teatro; 18 laboratórios; núcleo de Práticas Jurídicas; Clínica de Psicologia Aplicada; Empresa Júnior; Salão de Convivência; ampla Biblioteca com acervo de mais de 20.000 livros; estacionamento para 650 carros.

Em relação ao futuro, o professor Luciano Feijão planeja uma ampliação para 2017 de 03 novos prédios anexos, cada um deles contando com $2.500 \mathrm{~m}^{2}$ de área construída, onde cada um terá 16 salas de aula, oito laboratórios, e o próprio setor administrativo, para cursos futuros.

É uma potencialidade estrutural e tecnológica que não pode sobrepor à relevância do atendimento "face à face" com o aluno, do respeito e valorização de capital intelectual representando pelo grupo de professores comprometidos com a instituição e a mudança por meio da educação.

Para ilustrar esse grande momento, o professor Luciano Feijão concluiu "Está com quatro anos que eu faço esse prédio. Todo dia, todo dia, de segunda a sábado, cinco horas da manhã eu estou aqui, quem dá o primeiro bom dia aos funcionários sou eu, todo dia, de segunda a sábado, cinco horas estou aqui".

Essa realização faz parte do início da história desse espaço acadêmico, que passou a funcionar em fevereiro de 2016, com 08 turmas do curso de administração no período noturno, 20 turmas do curso de direito dividido entre os turnos da tarde e da noite; 10 turmas do curso de psicologia no turno da noite, e previsão para iniciar em agosto a primeira turma de curso de engenharia civil.

$\mathrm{Na}$ modalidade de Pós-graduação Lato Sensu, funcionarão os cursos de especialização nas áreas do direito e administração. Na Pós-graduação Stricto Sensu, dará continuidade o Curso de Mestrado Interinstitucional em Administração, resultado de uma parceria entre a Faculdade Luciano Feijão e a Universidade Vale do ItajaíUNIVALI, e o Mestrado Interinstitucional em Direito, parceria firmada com a Universidade Federal de Santa Catarina-UFSC.

Como planejamento futuro, o professor Luciano Feijão aguarda a visita in loco para o curso de enfermagem. O projeto pedagógico do curso de medicina está em processo de análise de viabilidade.

Em continuidade à parceria com a Universidade Federal de Santa Catarina-UFSC, foi submetido ao Colegiado do Programa de Pós-graduação em Direito, um projeto para um Curso de Doutorado-DINTER, que, se avaliado com viabilidade, será encaminhado a CAPES.

As prospecções futuras do professor Luciano Feijão é continuar contribuindo na construção de um país melhor por meio da educação, portanto, seu interesse é seguir em busca pela qualidade de um ensino que contribua para a mudança econômica e social da região e do estado do Ceará.

\section{O dilema}

A Faculdade Luciano Feijão apresenta uma estrutura física com alto padrão de qualidade. Tem um corpo docente composto em sua maioria de mestres e doutores, com carga horária em tempo parcial e integral. Muitos residem na Capital, Fortaleza, permanecendo em Sobral dois ou três dias por semana.

Atualmente, oferece os cursos de administração, direito e psicologia. O curso de Engenharia Civil está com inscrições abertas para o vestibular. Enquanto o curso de enfermagem aguarda-se a visita in loco para autorização. 
Contabilizando um total de três cursos em funcionamento, com previsão em curto prazo da entrada dos cursos de Engenharia Civil e Enfermagem.

Esse cenário direciona para um planejamento de transformação de uma Faculdade isolada, conforme o Decreto n. ${ }^{\circ}$ 5.773/06, para um centro universitário, que, segundo o Ministério da Educação, são as instituições de ensino superior pluri curriculares, abrangendo uma ou mais áreas do conhecimento, que se caracterizam pela excelência do ensino oferecido, comprovada pela qualificação do seu corpo docente e pelas condições de trabalho acadêmico oferecidas à comunidade escolar.

Atendendo as exigências do Ministério da Educação, para uma Instituição de Ensino Superior tornar-se um centro universitário, é necessário o pleno funcionamento de, pelo menos, oito cursos em consonância com o atendimento à legislação do Decreto n. ${ }^{\circ}$ 5.773/06. Os centros universitários credenciados têm autonomia para criar, organizar e extinguir, em sua sede, cursos e programas de educação superior.

Nesse sentido, a Faculdade Luciano Feijão, por sua atuação na integração do tripé da educação superior composto por ensino, pesquisa e extensão, em comunhão com o número de cursos já ofertados, tem oportunidade de continuar com um cenário prospectivo na criação de novos cursos para se transformar em um centro universitário. Com esse ensejo, o professor Luciano Feijão entende que o ingresso de cada curso é permeado por uma série de tomada de decisão que deve ser analisada em comunhão com as potencialidades e fragilidades impostas pelo mercado. Em outra perspectiva, o planejamento da IES vem sendo realizada nos últimos oito anos pelo fundador, a esposa e os seus três filhos, evidenciando um cenário de sucessão pautado em novos modelos contemporâneos de ensino e a interdisciplinaridade pedagógica. Assim, com a mudança para a nova sede, o professor Luciano Feijão passou a vivenciar algumas decisões que os levaram aos seguintes dilemas: permanecer como uma Faculdade isolada com oferta limitada de Cursos Superiores? Investir em novos cursos para chegar a Centro Universitário o mais rápido possível? Ou fortalecer os investimentos nos cursos em funcionamento?

\section{Notas de ensino}

\section{Objetivos educacionais do caso}

Este caso para ensino relata o desempenho de uma Instituição de Ensino Superior no interior do Ceará, que atua em um cenário altamente competitivo de ofertas de cursos superiores, e mostra possíveis indicadores que podem contribuir para superar tais desafios e tomar a decisão de se colocar no mapa da Educação do Brasil. Espera-se que a leitura, análise e discussão do caso orientem os estudantes nos seguintes temas e propósitos:

1. Identificar as possibilidades de tomada de decisão e propor viáveis soluções para resolução do dilema.

2. Analisar os aspectos comportamentais do gestor no que diz respeito a sua atuação como empreendedor.

3. Possibilitar uma reflexão sobre os fatores que influenciaram o gestor a identificar essa oportunidade de negócio.

4. Identificar as características empreendedoras do gestor que são preponderantes para a tomada de decisão estratégica.

5. Estimular um debate sobre o cenário das instituições de ensino superior privado e avaliar os mecanismos de sobrevivência necessários para a tomada de decisão estratégica.

\section{UTILIZAÇÃO RECOMENDADA}

Sugere-se que o caso seja utilizado, principalmente, com os alunos do curso de graduação em Administração ou áreas afins, especificamente nas disciplinas de Empreendedorismo, Tomada de decisão e Processo decisório. Justifica-se o uso do caso nessas disciplinas por estimular os alunos a refletirem e relacionarem o contexto teórico com a prática gerencial a partir de uma análise sobre os comportamentos, perfil e características empreendedoras, e a capacidade de tomada de decisão do gestor que atua em um segmento altamente competitivo de mais oferta que demanda.

\section{Fonte de obtenção dos dados do caso}

As informações foram coletadas com entrevistas semiestruturadas com o fundador professor Luciano Feijão, com a Diretora geral da Faculdade, Profa. Isabel de Aguiar Pontes e com o Vice-Diretor, Francisco Lúcio Feijão. A 
coleta documental efetuou-se mediante o Projeto Político Pedagógico do Colégio e do Projeto de Desenvolvimento Institucional da Faculdade Luciano Feijão.

\section{Dinâmica e agenda para discussão do caso}

A operacionalização dessa etapa, deve ocorrer por meio de um planejamento antecipado da leitura do caso e das sugestões apresentadas para suporte teórico. Orienta que o caso seja trabalhado ao longo de uma aula de, no mínimo, em uma aula de uma hora e cinquenta minutos de duração. Para isso, o tabela 1 sugere um planejamento sumarizado para viabilizar as discussões.

Tabela 1. Planejamento das discussões

\begin{tabular}{|c|l|}
\hline Duração & \multicolumn{1}{c|}{ Atividades } \\
\hline 15 min & $\begin{array}{l}\text { Apresentação geral do caso com seus pressupostos teóricos e a formação dos grupos } \\
\text { para as discussões. }\end{array}$ \\
\hline $30 \mathrm{~min}$ & $\begin{array}{l}\text { Contextualização do caso com a exposição dos objetivos propostos. Apresentação dos } \\
\text { questionamentos com as respectivas proposições teóricas. }\end{array}$ \\
\hline $30 \mathrm{~min}$ & Apresentação, discussão e alinhamento teórico com as respostas dos grupos. \\
\hline $15 \mathrm{~min}$ & Considerações finais com o fechamento do caso. \\
\hline
\end{tabular}

Fonte: Elaborado pelos autores (2018).

\section{Questões para discussão e análise teórica do caso}

Nesta etapa, o professor deve dividir a turma em até cinco membros, podendo variar conforme o tamanho. Sugerese, no planejamento proposto na figura 1, que o professor apresente os questionamentos a seguir, associando ao posicionamento dos autores referenciados no texto.

\section{Questão 1 - Quais as características comportamentais empreendedoras apresentadas pelo professor} Luciano Feijão que o impulsionaram a decidir sobre a criação de uma Instituição de Ensino Superior?

Para Schumpeter (1961), o empreendedor é um indivíduo que inova, é capaz de superar antigas "combinações", favorecendo o desenvolvimento econômico. Corroborando com esta análise, Fontenele et. al., (2010) defende que o empreendedor assume não apenas um papel central no avanço e desenvolvimento da economia e da sociedade, como protagoniza um papel essencial na evolução da vida empresarial e na substituição das empresas estabelecidas por novas organizações capazes de aproveitar as inovações.

Em complemento, Barreto (1998) defende que o empreendedorismo é a habilidade de criar e construir algo a partir de muito pouco ou do quase nada. Assim, o empreender é fundamentalmente um ato criativo. É a concentração de energia no iniciar e continuar um empreendimento. É o possuir de competências para descobrir e controlar recursos, aplicando-os de forma produtiva. Com uma visão congruente, Degen (1989) defende que ser empreendedor significa, acima de tudo, a necessidade de realizar coisas novas, pôr em prática ideias próprias, características de personalidade e comportamento que nem sempre são fáceis de encontrar.

Na visão de Filion (1999), o empreendedor é um ser social, produto do meio em que vive, fenômeno regional. Dolabela (1999) complementa, considerando como o motor da economia, agente de mudanças. É uma pessoa que imagina, desenvolve e realiza visões.

Para Dornelas (2008), a condução das ações do empreendedor está fundamentada na motivação singular, paixão pelo trabalho e necessidade de deixar um legado. Portanto, as características marcantes dos empreendedores estão sob o sustentáculo de três dimensões: realização: busca de oportunidades, iniciativa, persistência, aceitação de riscos e comprometimento. Planejamento: estabelecimento de metas, busca de informações, planejamento e monitoramento. Poder: persuasão, estabelecimento de rede de contatos, liderança, independência e autoconfiança. McClelland (1961) realizou uma pesquisa em diversos países, com o propósito de identificar características comuns entre em empreendedores de sucesso, o que chamou de Características do Comportamento Empreendedor (CCE). O modelo teste inicial continha 55 questões, porém, as que mais se destacaram foram: busca por oportunidade e iniciativa; persistência; comprometimento; exigência de qualidade e eficiência; correr riscos calculados; estabelecimentos de metas; busca de informações; planejamento; e monitoramento sistemático; persuasão e rede de contatos; independência e autoconfiança. 
A congruência entre estas características torna o empreendedor uma pessoa criativa, marcada pela capacidade de detectar oportunidades de negócios, estabelecer e atingir objetivos, contribuindo para o desenvolvimento econômico, social e cultural.

Nesse sentido, as referências teóricas sobre características empreendedoras apresentadas para esta discussão elencam um conjunto de contribuições para que os alunos possam destacar, em ordem de prioridades, as principais características que impulsionaram o professor Luciano a criar a instituição.

\section{Questão 2 - As atitudes empreendedoras do professor Luciano Feijão são determinantes para a tomada de decisão sobre tronar-se um Centro Universitário?}

Presume-se que o indivíduo com características comportamentais para criar novos negócios tenha atitude e convicção de que a sua decisão recebe influência dos ambientes interno e externo. Portanto, sua intenção em adotar determinados comportamentos deve estar fundamentada na proposta de mudanças individuais e sociais.

Para Fishbein e Ajzen (2000), a atitude consiste em uma disposição individual para responder ativamente a uma situação definida ou indefinida que expresse uma avaliação de cunho psicológico ou social, que necessariamente exija uma forma de prever e explicar o comportamento.

Acerca da atitude empreendedora, pode-se associá-la à compreensão de exploração de oportunidades projetada por Machado, Silva e Nascimento (2009), ao ressaltarem que a oportunidade pode ser entendida como uma situação identificada por um indivíduo capaz de empreender esforços psicossociais para aproveitá-la.

As oportunidades empreendedoras surgem, primeiramente, porque diferentes indivíduos possuem crenças diversificadas sobre o valor relativo dos recursos disponíveis, aspectos culturais, econômicos, (Kirzner, 1997; Filion, 1999). Sendo possível também o lugar ser uma referência ou indicador capaz de despertar novas reflexões e comportamentos associados à identificação de oportunidades por meio das potencialidade locais e do sentindo de pertencimento a esse espaço, o que promove a desejabilidade, que, segundo Shapero e Sokol (1982), representa as aspirações, desejos e expectativas, que estão restritas no imaginário do indivíduo.

A atitude empreendedora está intrinsecamente no comportamento de um indivíduo que apresenta forte autonomia para a ação, liberdade para trabalhar, detentor de potencialidades para assunção aos riscos (Pinchot \& Pellman, 2004; Hartman, 2006; Hamel \& Prahalad, 1995).

Na percepção de Heidman e Veit (2012, p. 25), "as atitudes são construtos hipotéticos que, apesar de inacessíveis à observação direta, podem ser inferidas por meio de respostas mensuráveis". Enquanto isso, Orr, Thrush e Plaut et al., (2013) defendem que a atitude é um estado em um sistema dinâmico que é reconstruído a partir de um conjunto de entradas, que atuam como representações do contexto social, ativando de forma imediata as crenças definidas na memória do indivíduo.

Considerando que a atitude requer uma experiência direta e indireta com um objeto atitudinal, (Ajzen, 2001), apresentando predisposição para responder de forma favorável ou desfavorável em relação à ação, Souza e Fracasso (2006) ressaltam que essa predisposição apreendida, ou não, para agir, influencia no indivíduo o desejo de inovar, agir de forma autônoma, criativa e com capacidade para assumir risco.

Nessa ótica, as referências teóricas expostas, apresentam aspectos que fundamentam a discussão sobre as atitudes empreendedoras demonstradas pelo professor Luciano Feijão no processo de tomada de decisão em tornar-se um Centro Universitário.

Questão 3 - As ações adotadas nos aspectos do ensino, pesquisa e extensão são indicadores de influência na tomada de decisão sobre tornar-se um Centro Universitário?

Para Ansoff (1977) as decisões estão estruturadas em estratégicas, que tendem a ser tomadas a partir de situações provocadas pela empresa e o ambiente. As decisões táticas estão relacionadas à estruturação dos recursos da empresa. As decisões operacionais que visam maximizar a eficiência do processo de conversão dos recursos.

É observável que, mesmo com visões distintas, todas as decisões apresentam ponto de convergência e complementaridade. O processo de decisão exige uma estruturação formal que deve ser compartilhada com detalhes consistente e transparente para todos os níveis de gestão e para os stakeholders.

As decisões são classificadas como programadas e não programadas (Simon, 1977), porém as organizações não podem se utilizar de uma classificação específica. No que concerne à tomada de decisão como processo de ação para esse estudo, as decisões estão conjugadas, em determinadas situações usam-se as de caráter único. Porém, as decisões em grande parte são tomadas em grupos, sendo que Gibson et al., (2006) defendem que os grupos geralmente demoram decidir, no entanto, a qualidade da decisão em grupo é de fundamental importância para o sucesso do resultado. 
Gomes, Gomes e Almeida (2002, p. 12-13) que afirmam: "tomar decisões complexas é, de modo geral, uma das mais difíceis tarefas enfrentadas individualmente ou por grupos de indivíduos, pois quase sempre tais decisões devem atender a múltiplos objetivos, e frequentemente seus impactos não podem ser corretamente identificados". Com base no exposto, e, em consonância com os estudos de (Hoppen, 1992; Tonn, 2003; Ansoff, 1977; Eberline \& Tatum, 2008; Regalado, 2014), sugere-se que as ações difundidas no processo do ensino, pesquisa e extensão descritas no caso apresentam contribuições que corroboram para a formação da decisão do professor Luciano Feijão em tornar-se um Centro Universitário.

Questão 4 - A participação da família com uma visão gerencial contemporânea poderá contribuir na formação de argumentos para a tomada de decisão do professor Luciano Feijão em relação a criar novos cursos e tornar-se um Centro Universitário?

Os gestores destinam a maior parte do seu tempo em tomadas de decisões que influenciam significativamente nos resultados da organização, especificamente os que ocupam posições estratégicas. Para Dittrich (2010) as decisões são tomadas quando distintas ações convergem para um evento ocorrer.

Os modelos clássicos de tomada de decisão apontam a racionalidade como variável determinante para os resultados das decisões. Assim, Árabe; Spitzeck (2014), orienta que uma tomada de decisão, quando analisada na perspectiva do macro ambiente e microambiente, apresenta maior probabilidade no alcance dos resultados estimados, seja por parte da empresa, seja por parte dos envolvidos no processo. Os gestores constantemente recebem informações que os levam a tomar decisões com o propósito de solucionarem situações-problemas para evitar possíveis comprometimentos na sustentabilidade da organização ou para gerar futuras vantagens competitivas.

Simon (1972) defende que toda e qualquer decisão é permeada por uma série de alternativas comportamentais ou estratégica implementada em determinado momento para situações especificas e onipresente nas organizações, no contexto individual, grupal e organizacional (Simon, 1972; Cunha \& Rego, 2003).

O gestor deve compreender que as decisões não são indicadores de problemas, mas um mecanismo para resolução de um problema com o propósito de cumprir os objetivos fixados na missão e a visão da organização.

Para Miragia (2008) muitos gestores atribuem a tomada de decisões a uma certa conotação negativa, quando se faz referência ao surgimento de um problema que impacta nos objetivos organizacionais. Porém, o autor orienta que essa percepção de problema deve ser entendida como uma potencialidade para o crescimento e o desenvolvimento e não como uma ameaça organizacional.

Nesse sentido, o gestor deve analisar os aspectos ambientais internos e externos e avaliar se tal situação aponta para uma abordagem com traços constituintes de ameaças ou oportunidades para o resultado planejado.

O processo de tomada de decisão é uma ação singular de cada gestor que deve estar associada aos propósitos organizacionais. Observa-se que os estudos sobre tomada de decisão permanecem com uma rotina linear que vem perpassando décadas utilizando-se das mesmas etapas para se chegar ao processo decisório (Mintzberg et al., 1976; Bazerman \& Moore, 2010).

Para Simon (1960) o processo decisório é formado por três vertentes classificadas como: inteligência, concepção, seleção e implementação. Nessa ótica, para se tomar uma decisão racional, o gestor deve elencar as alternativas existentes, identificar suas consequências e conduzir a ação considerando também os aspectos subjetivos que podem colaborar no processo decisório.

Assim, para que o gestor tomador de decisão escolha a alternativa concernente aos objetivos da organização, é necessário elencar as possibilidades existentes, e identificar prováveis consequências que influenciarão em decisões futuras.

Considerando os argumentos de Simon (1960), em congruência com as ideias dos demais autores citados, pode-se afirmar a existência de elementos teóricos que fundamentam a participação da família na decisão do professor Luciano Feijão em tornar-se um Centro Universitário.

\section{Questão 5 - À luz das condições descritas no caso, sobre a capacidade empreendedora do professor Luciano Feijão, o que o futuro reserva para a Faculdade Luciano Feijão?}

Drucker (1987) defende que os empreendedores estão sempre buscando mudanças, reagem a elas e a exploram como sendo uma oportunidade, nem sempre vista pelos demais. Hisrich et al. (2009), o empreendedor é a pessoa que identifica oportunidades e cria algo inovador sob condições de incerteza, assumindo os riscos envolvidos, imbuídos de persistência, visão de futuro, envolvem o processo de empreender.

Com uma visão da contemporaneidade, Boava et. al., (2010) defende que a essência do empreendedorismo está centrado na liberdade, porque é ela que impulsiona o ser, independente do motivo que foi deflagrador do desejo de empreender. O ser somente será livre, se estiver constantemente empreendendo. 
Boava (2010) apresenta que a origem de todas as afirmações sobre empreendedorismo é advinda da economia. E como os principais temas à luz de vários teóricos como: Cantillon (1955), que utilizou o termo entrepreneur para denominar o empresário que corre riscos em função de sua atividade, seja o produtor, o atravessador ou o comerciante. É o empreendedor que compra a matéria-prima a um preço determinado e vende o produto a um preço incerto.

Quanto à contribuição de Smith (1996) o empreendedor tem o propósito de produzir dinheiro, sendo o proprietário capitalista, um fornecedor de capital, um administrador situado entre o trabalhador e o consumidor. Para Say (1971) o empreendedor é o condutor da inovação.

Para Boava (2006), empreender não reside instância da vontade ou ideia do indivíduo, ou mesmo na sua consciência, mas sim na potencialidade que tal indivíduo tem de agir de forma autônoma, buscando seus objetivos. $\mathrm{Na}$ ótica da teoria apresentada, sugere-se que os alunos tomem como base para essa discussão, e considere que, conforme descrito no caso, o professor Luciano Feijão, enquanto empreendedor de visão, é capaz de romper com aquilo que the proporciona segurança e estabilidade para explorar novas oportunidades.

\section{Referências}

Ajzen, I. (1991). The theory of planned behavior organizational behavior and human. Decision Processes, v. 50, p. 179-211.

Ajzen, I.; Fishbein, M. (2000). Attitudes and Attitude-Behavior Relation: reasoned and automatic processes. In. W. STROBE and M. HEWSTONE (ed.), European Review of Social Psychology, p. 1-33, John Wiley and Sons.

Ansoff, H.I. (1977). Estratégia empresarial. São Paulo: McGraw Hill.

ÁRABE, M. P.; SPITZECK, H. H. (2014). A influência da história de vida na tomada de decisões sustentáveis por lideranças corporativas: um estudo de caso. In: XXXVIII Encontro Nacional de PósGraduação em Administração, 2014, Rio de Janeiro. Anais...Rio de Janeiro.

Barreto, L. P. (1998). Educação para o empreendedorismo. Educação Brasileira.

Bazerman, M. H. (2004). Processo Decisório: para cursos de Administração, Economia e MBAs. Rio de Janeiro: Elsevier Editora.

Boava, D. L. T.; Macedo, F. M. F. (2006). Estudo sobre a essência do empreendedorismo. In: Encontro Nacional de Pós-Graduação em Administração, 30, Salvador. Anais... Salvador: ANPAD.

BRASIL. MINISTÉRIO DA EDUCAÇÃO. Disponível em http://www2.mec.gov.br/sapiens/portarias/dec5773.htm. Acesso em: 29 de Abril, 2016.

Cantillon, R. (1955). Essai sur la nature du commerce en général, London: Fetcher Gyler.

Cunha, M. P., \& Rêgo, A. (2003). Comportamento organizacional e gestão. Instrumento de medida. Lisboa.

Degen, R. J. (1989). Empreendedor: fundamentos da iniciativa empresarial. São Paulo: MacGraw-Hill. Dolabela, F. (1999). Oficina do empreendedor. São Paulo: Cultura Editores.

Dornelas, J. C. A. (2008). Empreendedorismo corporativo: como ser empreendedor, inovar e se diferenciar na sua empresa. 2. ed. Rio de Janeiro: Elsevier.

Dittrich, A. (2010). Análise de consequências como procedimento para decisões éticas. Perspectivas em análise do comportamento, 1(1), pp. 44-54.

Drucker, P. F. (1987). Inovação e espírito empreendedor. São Paulo: Pioneira.

Eberlin, R. J.; Tatum, B. C. (2008).Making just decisions: organizational justice, decision-making, and leadership. Management Decision, 46(2), pp. 310-329.

Filion, L. J. (1999). Empreendedorismo: empreendedores e proprietários-gerentes de pequenos negócios. RAUSP, São Paulo, v. 34, n. 2, p. 05-28, abr./jul.

Fontenele, R. E. S. (2010). Empreendedorismo, competitividade e crescimento econômico: evidências empíricas. Revista da Administração Contemporânea, v.1 4, n. 6, nov./dez.

Gibson, J. L.V.; Ivancevich, J. M.; Dornelly, J. H.; Konopaske, R. (2006). Organizações, Comportamento, Estrutura e Processo. McGraw Hill.

Heidemann, L. A.; Araujo, I. S.; Veit, E. A. (2012). Um referencial teórico-metodológico para o desenvolvimento de pesquisas sobre atitude: a Teoria do Comportamento Planejado de Icek Ajzen. Revista electrónica de investigación en educación en ciencias - REIEC, volume 7, n 8, p. 1-10. 
Hisrich, R. D.; Peters, M. P.; Shepherd, D. A. (2009). Empreendedorismo. 7. ed. Porto Alegre: Bookman.

Hoppen, N. (1992). Resolução de problemas, tomada de decisão e sistemas de informação. Caderno de Administração Geral Programa de Eficácia Gerencial, Porto Alegre.

Gomes, F. A. M.; Gomes, C. F. S.; Almeida, A. T. (2002). Tomada de Decisão Gerencial: Enfoque Multicritério. São Paulo: Editora Atlas.

Kirzner, I. M. (1997). Interview with. Austrian Economics Newsletter, 17(1).

Machado, H. V.; Silva, T.; Nascimento, M. R. (2009). Empreendedorismo e redes: a exploração de oportunidades em associações comerciais. In: XXXIII Encontro Nacional de Pós-Graduação em Administração. São Paulo.

Mintzberg, H.; Raisinghani, D.; Théorêt, A. (1976). The structure of 'unstructured' decision processes. Administrative Science Quarterly. Vol. 21, p. 246-275.

Miragaia, D. A. (2008). Modelos organizacionais para a tomada de decisão em contexto de mudança - Contributo da Motricidade Humana, Covilhã, Universidade da Beira Interior.

Mcclelland, D. C. (1961). The achieving society. Princeton, NJ: Van Nostrand.

Orr, M. G.; Thrush, R.; Plaut. D. C. (2013). The Theory of Reasoned Action as Parallel Constraint Satisfaction: Towards a Dynamic Computational Model of Health Behavior, V. 12, N.19. pp 8(5). PROJETO DE DESENVOLVIMENTO INTERINSTITUCIONAL. Disponível em: www.flucianofeijao.com.br/. Acesso em: 28 abril. 2016.

PROJETO POLITICO PEDAGÓGICO. Disponível em: www.lucianofeijao.com.br/. Acesso em: 28 abril. 2016.

Regalado, A. (2014). The Power to Decide - What's the point of all that data, anyway? It's to make decisions, MIT Technology Review - Business Data and Decision Making: Business report, Jan., p. 1-15.

Say, J. B. (1971). A Treatise on Political Economy or the Production, Distribution and Consumption of Wealth. New York: A. M. Kelley Publishers (First edition 1803).

Simon, H. A. (1960). The New Science of Management Decision. New York, NY: Harper and Row. Simon, H. A. (1979). Comportamento administrativo: estudo dos processos decisórios nas organizações administrativas. 3. ed. Rio de Janeiro: Ed. da FGV.

Souza, E.C.L.; Fracasso, E. (2009). Empreendedorismo: conceitos, abordagens, construção de escalas de mensuração. Revista Turismo Visão e Ação - Eletrônica, v. 11, nº 3, p. 358 - 374, set/dez.

Shapero, A.; Sokol, L. (1982). The Social dimensions of entrepreneurship. In: Encyclopedia of Entrepreneurship. Englewood Cliffs, NJ: Prentice-Hall Inc.

Schumpeter, J. A. (1982). A teoria do desenvolvimento econômico. São Paulo: Abril Cultural.

Smith, A. (1996). A riqueza das nações. Investigação sobre sua natureza e suas causas (Livro I). São Paulo: Abril Cultural.

Timmons, J. A. (1994). New venture creation. 4. ed. Boston: Irwin McGraw-Hill.

Tonn, B. E. (2003). The Future of Future Decision Making. Futures, v. 35, n. 6, p. 673-688, junho. 